\title{
Philosophical Enquiry into Environmental Policy of Ethiopia: Challenges and Prospects
}

\author{
Taye Birhanu \\ Department of Philosophy, Faculty of Social Sciences, Addis Ababa University, Addis Ababa, Ethiopia
}

Email address:

tayex2014@gmail.com

\section{To cite this article:}

Taye Birhanu. Philosophical Enquiry into Environmental Policy of Ethiopia: Challenges and Prospects. American Journal of Environmental Protection. Vol. 8, No. 6, 2019, pp. 121-132. doi: 10.11648/j.ajep.20190806.13

Received: May 13, 2019; Accepted: June 13, 2019; Published: December 4, 2019

\begin{abstract}
The issues related to environmental problems and challenges such as climate change and global warming in particular and the issue of environmental crisis in general had been given very little attention until very recently which is, of course, insignificant compared to the seriousness and intensity of the problem. The main objective that has been addressed in this thesis is the establishment of sound arguments that could serve as a ground on which the environmental policy of Ethiopia could be rationally criticized. The problem dealt with in this thesis could be best defined and explained by looking at the larger picture of the issue of which it is part and parcel. The larger picture in this context represents or depicts the global environmental crisis that is resulting in the suffering of all that exist in the natural world. In attempt to resolve this common crisis we have been experiencing commitments of the countries of the world either individually or collectively through creating joint ventures that resulted in a number of initiatives and conventions regarding environmental issue. However, it has been argued throughout this thesis that most of the philosophical foundations and principles and values underlying those commitments made so far are problematic by themselves. Accordingly, the case of conducting philosophical enquiry into the environmental policy of Ethiopia has to be understood as part of the larger picture of the problem that has got more emphasis here for the sake of making it as specific as possible, otherwise it would have been very difficult to manage to arrive at the conclusions made in this thesis. Theoretically and conceptually this thesis is founded on the main argument in the study of environmental ethics that claims the study of environmental ethics and engaging in philosophical discourses through formulating sound arguments for and against the major approaches and theories of the environmental ethics play a pivotal role in the attempt to come up with an ethical environmental policy that guides and governs the relations between human beings and the natural environment in a manner that does justice to the environment. In general, in this thesis it has been argued either explicitly or implicitly that the environmental policy of Ethiopia is not ethical seen from the perspective of the holistic environmental ethics and principles of environmental justice.
\end{abstract}

Keywords: Natural Environment, Environmental Ethics, Environmental Policy, Anthropocentrism, Intrinsic Value, Extrinsic Value

\section{Introduction}

\subsection{Background of the Study}

The issue of environmental crisis in general and environmental problems such as climate change and global warming in particular have been major challenge to the international community as well as to non-human members of the natural environment, especially being worsened by irresponsible human activities and exacerbated by rapid population growth, industrialization and misconceived conventional assumptions related to the principles that ought to govern the relationship between human beings and the natural environment. As a result we have experienced a number of commitments from various institutions, scholars, individual states and joint ventures of the international community intending to overcome the challenges. One among these commitments is that of environmental philosophy and environmental ethics being provided as an independent field of study in higher institutions of education across the world. Even though this academic discipline was introduced to the education curriculum very recently, various 
philosophers had already been concerned with environmental issues several decades back where they emphasized the relationship between human beings and the natural environment. According to Alasdair Cochrane, "while numerous philosophers have written on this topic throughout history, environmental ethics really only developed into a specific philosophical discipline in the 1970s" [1]. Nowadays, the issue of averting environmental crisis has become a top priority agenda for the international community being manifested through organizing conferences and summits as well as by coming up with various domestic and international initiatives concerning how to govern the relationship between human beings and the natural environment. Boutros Boutros-Ghali, speaking as the UN Secretary-General, closed the Earth Summit stating:

The Spirit of Rio must create a new mode of civic conduct. It is not enough for man to love his neighbor; he must also learn to love his world. We must now conclude an ethical and political contract with nature, with this Earth to which we owe our very existence and which gives us life [2].

To this end, Ethiopia has also been taking part in the joint ventures made by the international community with an attempt to devise a policy that guides the management of the natural environment through shaping and regulating the behaviors and actions of individuals and organizations in a manner that is environmentally friendly.

Ethiopia, as an independent political entity has had its own national environmental policy since 1997 . However, this does not mean that the country did not have proclamations and legislations regarding the issue of how to protect, conserve, and preserve the natural environment. But those legislations were organized and administered by different sectors like the Ministry of Health where there was no independent institution that was neutrally responsible to operate across sectors on the issues related to the natural environment of which most were repealed by the present environmental policy and legislations. A new Ministry called Environment, Forest and Climate Change of the Federal Democratic Republic of Ethiopia (FDRE) was established in this 2014, merging the former responsible institution called Environmental Protection Authority (EPA) and Forest wing of the Ministry of Agriculture (MOA) so as to tackle the increasing and pressing environmental problems and climate change which latter on changed into commission in 2019. (Informant: Dr. Ayele Hegena). He added that this instability of the institution has negatively affected our institutional capacity. Environmental Policy of Ethiopia (EPE) was devised by the then responsible organ EPA in 1997. The 2011 FDRE Climate-Resilient Green Economy (CRGE) came to existence as an additional comprehensive document next to the EPE. Another legal document of the country concerned with the issue of Environment worth mentioning here is that of "Environmental Protection organs Establishment proclamation No.295/2002". In addition to these legislations, there are two more FDRE recently enacted proclamations on the issues of environment adopted in the same year with the latter one. These are: the "Environmental Impact Assessment
Proclamation No. 299/2002" and "Environmental Pollution Control Proclamation No.300/2002" respectively. These documents and some of the relevant provisions, articles and sub-articles of the 1995 FDRE constitution that laid base for legal frameworks of the environmental policy and related legislations shall be discussed, analyzed, and critically evaluated in chapter three in detail together with some of the relevant international initiatives ratified by Ethiopia.

Though these legal and policy documents of Ethiopia enacted on the issue of environment indicate that the country is committed to contribute its part in the attempt to resolve environmental crisis domestically and internationally, I argue that it is too late when we look at the issue date of these legislations and policy documents compared to the severity and persistency of the environmental problems and challenges both at home and internationally. For instance, the three proclamations of the country regarding the issue of environment listed above were enacted very recently with in the same year, i.e. 2002. Even the 1997 EPE itself came too late for me, because the country had been long a modern sovereign state having independent institutions, policies and strategies for various sectors, particularly under the last three consecutive regimes: Emperor Haile Selassie I; Military regime and the current Ethiopian Peoples' Revolutionary democratic Front (EPRDF). Another indicator that the issue of environment got little attention and excluded for a long period of time from the realm of the country's national policies and strategies is that even after the EPE was devised in 1997 there was no an independent ministerial institution in place to enforce its implementation and facilitates the necessary revision when the need arises except an agency called EPA up until the coming of the newly established FDRE Commission of Environment, Forest and Climate Change. However, though it is too late, this newly established independent ministerial institution seems to capture the need for the existence of an effective and comprehensive institution that independently operates across the other sectors in order to make sure that their behaviors, actions and decisions conform to the socio-economic development that is environmentally friendly, sound and justifiable. Because other things being equal as the name of the institution indicates it intends to focus on three top priority separate agendas of the domestic and international community, but highly interdependent issues: environment, forest and climate change.

The policies, strategies, programs, legislations, and proclamations of the FDRE related to the issue of Environment had their own respective frameworks, guidelines, goals, objectives, directives, philosophical and theoretical roots/foundations, and as well principles and values underlying their coming to existence, which I shall extensively discuss in chapter three of my thesis. In this introductory chapter, what I am trying to do is introducing the policy and legal documents that I shall rely on for the purpose of critically evaluating the underlying philosophical and theoretical foundations, standards, values and principles of the overall national environmental policy of Ethiopia as 
well as the role and value of indigenous world views of the local communities in the process of the formulation and implementation of these legal and policy documents so as to judge whether environmental policy of Ethiopia is ethical on the basis of ethical theories, perspectives, principles and standards that are embedded in both modern environmental ethics and indigenous world views of various Ethiopian cultural groups related to the environment that seek to justify actions and behaviors of human beings when it comes to their interaction with the natural environment.

I strongly believe that the responsibility of averting global environmental crisis cannot be fulfilled by acting individually as a country. However, there must be environmental justice where every actor (state and non-state) internalizes its own environmentally irresponsible actions and is at the same time committed to pay its own fair share so as to compensate the injustice that it has done to the natural environment. But, nowadays, it is quite common to experience environmental injustice where locally and internationally dominant groups, states, governments, donors and Multinational Corporations (MNCs) act in a manner that is environmentally irresponsible and unfriendly in order to satisfy their respective selfish interests. When it comes to the case of Africa, the suffering being faced from such an environmental crisis is shocking, and the case of Ethiopia is not exceptional. Munyaradzi Felix Murove argues:

While industrialized countries are responsible for massive pollution, much of the African continent is experiencing a level of environmental degradation and wildlife depletion equally alarming for welfare of future generations. Yet traditional African ethics recognizes the existential bond between people and environment, the debt any generation owes its fore bears and its consequent responsibility to posterity [3].

In developing countries like Ethiopia, there has been a tendency to exclude the local communities in particular and the general public in general from taking part in policy debates, revision, discussions and initiatives for various political and economic reasons while devising their respective national policies and strategies. Even when it comes to the case of Ethiopia some scholars argue that the lack of public participation ranges from not being aware of the points addressed in the policies to being largely excluded from the implementation process. According to Melaku Bekele:

The wider public generally has limited access and awareness of the sectorial policies and implementation modalities in Ethiopia. However, if different stakeholders are to engage policy, either by way of research, public debate, negotiation, or consultation and cooperation, they need to have easy access to such policy data, preferably in a userfriendly format [4].

Indigenous environmental ethics and the existing socioeconomic and political realities did not get the attention and consideration that they deserve being overshadowed by the interests and influence of economically and politically powerful sate and non-state actors in most developing countries. The same thing holds true when we come to the case of Ethiopia where indigenous environmental ethics was neglected while formulating and implementing policies and legislations regarding the environment though the indigenous environmental ethics possesses a number of good practices regarding protection of the environment that the national environmental policy could learn a lot from. Workineh Kelbessa argues:

The British colonies of East Africa and the U.S. influenced environmental conventions during the imperial era. The military government associated itself with the Soviet block from 1974, whereas the current government has appealed to the West and institutions such as the World Bank, the IMF, and the like since 1991 [5].

Hence, the major aim of this thesis is conducting a thorough and rationally justifiable philosophical enquiry into environmental policy of Ethiopia emphasizing theoretical frameworks, philosophical foundations, standards, directives, goals, objectives, and values and principles underlying the legal and policy documents of the country mentioned above and the rest related to environmental issue in order to judge whether the policy is ethically plausible and morally compelling enough to guide and govern the relationship and interaction between human beings and the natural environment which shall be discussed in detail in the forthcoming sections.

\subsection{Statement of the Problem}

As it is already highlighted in the background section, indigenous perspectives of the society related to the preservation and conservation of the natural environment, local stakeholders and domestic socio-economic and political realities, contexts, and settings were marginalized and often excluded from the act of environmental policy framing, process and debate in Ethiopia. Let alone the majority of poor "peasant farmers" and other ordinary portions of the society, the environmental policy of Ethiopia has been bitterly criticized for not incorporating experts from various relevant professions and institutions like University during the policy debate. James Keeley and Ian Scoones argue that "Soil erosion, biologists, agronomists, economists and others all make inputs into the environmental policy debate, (but this is not the case in Ethiopia) [6].

I have also reservations on the philosophical foundation of the environmental policy Ethiopia as well as on some of the goals, objectives, and principles that serve as the pillars of the policy which I shall raise in detail in the forthcoming sections. This thesis is partly stimulated by the fact that most of the time indigenous environmental ethics and local knowledge regarding how to protect, preserve, and conserve the natural environment were neglected and even excluded from the environmental policy debates, process of formulating it and its implementation in Ethiopia. Allan Hoben argues:

The highly asymmetric power relationship between colonial regimes and Africans and, after independence, between donor's representative and Africa's nascent 
governmental elites has prevented policy makers from learning form resource users, ordinary farmers and pastoralist [7].

I believe that underestimating the role of indigenous environmental ethics and local knowledge that are inherent in the people's cultural values has been greatly affecting the contextual relevance of Ethiopia's environmental policy to the existing actual socio-economic, cultural and political situations of the country. Because I think that every society gives credit and value for its own customs, traditions, psychological make-up, moral values and norms than any other adopted way of life which in turn makes it convenient to realize and internalize policies and strategies having roots in those customs and traditions. However, this does not mean that we need to accept traditions, customs, and moral norms and values of ours and of others for granted. But rather we have to evaluate them critically and rationally so that it we can justify and accept the ones plausible and compatible with the principles and values that are environmentally sound and friendly. In other words, those actions and behaviors that have proper care and due respect for all forms of life.

\subsection{Objectives of the Thesis}

\subsubsection{General Objective}

The general objective of this thesis is to conduct a philosophical enquiry into the environmental policy of Ethiopia through emphasizing the plausibility of the philosophical foundation on which the policy is founded as well as the underlying overall goal, objectives, principles, and claims that serve as the pillars of the policy with an intention to critically evaluate whether the environmental policy of Ethiopia is ethical followed by formulation of reliable general conclusions and alternative principles and standards.

\subsubsection{Specific Objectives}

In addition to the above mentioned general objective, the thesis has the following specific objectives:

1. To briefly present and analyze the process of the environmental policy formulation and development in Ethiopia;

2. To critically assess the substantive contents of the environmental policy of Ethiopia vis-à-vis the major theories and approaches of environmental ethics;

3. To critically evaluate and judge whether the environmental policy of Ethiopia is ethical from the perspective of the principle of environmental justice;

4. To identify the major limitations and qualities of the environmental policy of Ethiopia;

5. Last but not least, to come up with sound cross-cutting conclusions, specific, applicable and relevant possible solutions and suggestions as well as recommendations that might help in overcoming the challenges facing the policy and at the same time enable all the concerned bodies to make use of the available opportunities to sustain the qualities that the policy possesses.

\subsection{Research Questions}

This thesis aims at addressing the following key research questions.

1. Did all the concerned bodies and stakeholders take part in the debate and the process of making of the environmental policy of Ethiopia?

2. Are there external dominant interests and actors that might have influenced the formulation, interpretation and implementation of the environmental policy of Ethiopia?

3. Is Ethiopian environmental policy ethically plausible and morally permissible from the perspective of the principle of environmental justice?

4. What are the major limitations and qualities of the environmental policy of Ethiopia?

5. Are there viable solutions, suggestions, and recommendations that might help to overcome the challenges facing the policy and to seize the available opportunities of enhancing its status in maintaining environmental justice?

\subsection{Definitions of Key Terms and Concepts}

\subsubsection{Environment}

Prior to getting into the details of the issues related to environmental ethics and environmental policy, I think, it would be logical to begin with definitions and interpretations of key terms and basic variables of the study. One of these important terms is "environment". Various scholars have defined the term "environment" from their own respective perspectives. Now, I shall present a few among the many definitions given to the term "environment" in line with my own understanding and critique of the entertained ideas related to what we mean by the term "environment". Etymologically defined, the term "environment" is derived from the French word "environ" which means "surrounding". Our surrounding includes biotic factors like human beings, plants, animals, microbes, etc. and abiotic factors such as light, air, water, soil, etc. According to Sitinuraisyah Kalavathy [8], "environment" refers to a complex of many variables, which surrounds human beings as well as the living organisms. It includes water, air and land and the inter relationship which exists among and between water, air and land and human beings and other living creatures such as plants, animals and microorganisms. She further suggested that the term "environment" consists of an inseparable whole system constituted by physical, chemical, biological, social and cultural elements, which are interlinked individually and collectively in myriad ways. When we look at Kalavathy's definition of the term "environment", it is comprehensive and also gives due emphasis to what we collectively call the natural environment, unlike the former definition, which makes the latter more relevant to and complementary with the context of my thesis. Kumbar Kumarawsamy [9] on his part stated that the "natural environment" consists of four interlinking systems namely, the atmosphere, the hydrosphere, the lithosphere and the biosphere. He also 
argued that these four systems are in constant change and such changes are affected by human activities and vice versa. This definition is also vital for the purpose of this study, since it explicitly gives room to the issue of the interaction between human beings and other members of the natural environment. I believe that the term "environment" could be applied to issues that are beyond the natural environment, because we can speak of the physical environment too in the broader sense of the term. However, I shall use the term in its strict sense for the purpose of my thesis; mainly to interchangeably apply the term with that of the term "natural environment" by stressing the issues related to the relationship and interaction of human beings and other entities of the natural world.

According to the FDRE "Environmental Protection Organs Establishment Proclamation No. 295/2002", the term "environment" refers to the totality of all materials whether in their natural state or modified or changed by human, their external spaces and the interactions which affect their quality or quantity and the welfare of human or other living beings, including but not restricted to, land atmosphere, weather and climate, water, living things, sound, odor, taste, social factors, and aesthetics. I thought that this definition is more up to date, comprehensive and well-articulated compared the aforementioned definitions of the term. Therefore, I shall use this definition as an operational definition of the term "environment" throughout my thesis.

\subsubsection{Environmental Policy}

Another important concept that has to be dealt with or worth mentioning here is the term "environmental policy". Under this section, we shall see the general meaning and the process of development of an environmental policy briefly by emphasizing only the main points that are relevant to the purpose of this thesis. "Environmental policy is the commitment of an organization or government to the laws, regulations, and other policy mechanisms concerning environmental issues" [10]. This definition gives emphasis to the commitment of the organ devising the policy which is very important for the implementation of the policy's strategies and programs effectively. Apart from being committed, the policy makers should also possess the willingness to allow the local communities, various concerned bodies and stakeholders to take part in the procedures, discussions and debates that have to be followed while devising an environmental policy which results in alleviation of the problem from its root. Yoshida Fumikazu argues:

If we are to have any hope of overcoming the diversifying problems that affect the environment, many actors will have to play a part, not only governments but citizens, too, and of course, the corporations and the various actors will need to make use of a variety of policy instruments [10].

Therefore, in order to achieve the common goal of tacking global environmental crisis, individual states and other non-state actors need to work hand in hand by taking into account the above mentioned preconditions while devising national or regional environmental policy.
Particularly, the developing countries need to contextualize their respective national environmental policies in a manner that is compatible with the world views of the local communities that are environmentally friendly; followed by giving room for domestic cultural, socio-economic and political realities, engaging concerned professionals, and other local, regional and international stakeholders. This is due to the fact that the issue of environmental crisis is one of the trans-boundary challenges that demand cooperation among individual states in particular and the international community in general.

\subsubsection{Environmental Ethics}

Environmental ethics is a recent academic discipline which is one of the various fields of studies categorized under Philosophy, though the issue have been dealt with a number of philosophers explicitly or implicitly throughout the history of the subject. It is a body of knowledge that undertakes a philosophical enquiry into the very existence and reasons behind positions, claims and views relating to the natural environment. Environmental ethics is both theory and practice about how human beings ought to behave and act in their interaction and relationship with the natural environment, emphasizing appropriate concern for, values in, and duties concerning the natural world.

\subsubsection{Anthropocentrism}

Anthropocentrism is the school of thought that holds the belief that human beings, their interests, values, benefits and well-being are the sole grounds of moral concern and that they are the sole rightfully entitled to moral standing. Weak or moderate anthropocentrism, unlike the former, does not consider the natural environment as a means to human ends although it puts human beings at the center. It holds the belief that the natural world and its inhabitants possess value and deserve a due concern and proper care. It also takes into consideration the practical interaction and relations between human beings and the natural environment, however, it does not claim that every kind of human exploitation of the natural environment is immoral. On the other extreme, metaphysical or teleological anthropocentrism is the school of thought that claims everything that exists was made to keep and satisfy the interests of human beings and to realize their well-being.

\subsubsection{Intrinsic and Extrinsic Values}

An intrinsic value, sometimes called non-instrumental value refers to the value of non-human forms of life for no any other reason beyond themselves; not to regard preserving life as means to an end, but rather as an end in itself. On the other hand, extrinsic value or instrumental value is a value attributed to something due to its benefits or usefulness to human beings, as a means to an end. Even though these values are expressions that could be used in a variety of ways in environmental ethics, the above indicated definitions of the concepts are applied as operational or working definitions for the purpose of this thesis. 


\section{Critical Evaluation of the Environmental Policy of Ethiopia}

\subsection{Analysis and Critical Assessment of the 1997 Environmental Policy of Ethiopia}

\subsubsection{Analysis and Critical Evaluation of the Overall Goal and Objectives of the Policy}

Under this section, I shall present and examine some of the main goals, objectives, and guiding principles of the environmental policy of Ethiopia that are relevant incase that they could explain other specific issues arising from them. The environmental policy of Ethiopia in its section 2.1 states:

The overall policy goal is to improve and enhance the health and quality of life of all Ethiopians and to promote sustainable social and economic development through the sound management and use of natural, human-made and cultural resources and the environment as a whole so as to meet the needs of the present generation without compromising the ability of future generations to meet their own needs [11].

From this general or overall goal of the environmental policy of Ethiopia we can easily detect that the policy is purely anthropocentric or human centered because other objectives, guiding directives, and principles and values of the policy are derivatives of this general or overall goal. The first reason that makes it purely anthropocentric or human centered policy is that it is explicitly and primarily concerned with the mere enhancement and improvement of the health and quality of life of all Ethiopian citizens. That means it totally marginalized or even excluded the concern for other entities in the natural environment or it overemphasized the interest of human beings at the expense of plants, animals, species, and ecosystems with whom human beings must have been considered as plain members or residents of the natural environment. The second reason that shows us that the policy is founded on anthropocentric view of the environment is that it is primarily concerned with achieving and promoting social and economic development using both natural and human made elements of the environment as means to human ends which implies that the policy explicitly denies the intrinsic value of nature. Moreover it stresses the instrumental value of the environment for the present generation and the generation to come (of human beings). For me this clearly shows that the policy is driven by mere socio-economic or instrumental values of the natural environment than protecting it for its own sake which strives to secure selfish human interests to the extent of claiming that the need of the next human generation should not be compromised in the name of sustainable development with no recognition for the proper care and respect that other forms of life deserve. Hence, I suggest an alternative phrase that could replace the term "life of all Ethiopians" used in the overall goal of the policy indicated above that is "life of all entities that exist in the natural environment that fall within the boundary of Ethiopia".

The specific objectives of the environmental policy of
Ethiopia emanating from the above indicated overall goal of the policy also reflect and reinforce the anthropocentric view of the environment or the idea that plants, animals, species, and ecosystems in general are assigned merely with instrumental values or serve as only means to human endslacking values or goodness in themselves or for their own sake. Almost all the objectives emphasize the need to preserve and conserve or protect the environment for the sake of socio-economic and development in the life of human beings giving no room for proper care and respect for other forms of life. For example, one of the specific objectives stated in section $2.2 \mathrm{i}$ of the environmental policy of Ethiopia is to "Raise public awareness and promote understanding of the essential linkages between environment and development" [11]. This specific objective of the policy also stresses the importance of teaching the society in order to enhance their awareness relating to the environment. But what makes it terrible here is that the purpose of enhancing the public awareness is to convince them that they should preserve and conserve the natural environment for the sake of human development, not for the sake of according proper care and due respect that other forms of life in particular and the nature in general deserve. I think that is why some scholars are against the usage of the terms "preservation" and "conservation" when it comes to the issue of caring for the environment. Rather they suggest the term "protect" because they believe that the former two are value laden in that they both imply that humans should save the environment so that the present and the future generations of human beings rely on it to satisfy their needs and wants which also addresses the issue of sustainable development (Informant: Belachew Hailemariam). Therefore, even though I agree with the idea reflected in the overall goal of the environmental policy of Ethiopia that we need to protect the environment, but I do not share its idea that claims we should do that from the point of view of merely making use of the natural environment instrumentally for the sake of reaching our socio-economic ends. Because I believe that we ought to extend and expand some intrinsic values that we aspire for ourselves to other entities in the natural environment, for example, providing proper care and due respect for life in general (that of human beings and other forms of life). Therefore, up on rejecting this specific objective of the policy I propose an alternative specific objective that states "Raise public awareness and promote understanding of the essential proper care and due respect that all entities that exist in the environment deserve regardless of their benefits to humans".

\subsubsection{Analysis and Critical Evaluation of Key Guiding Principles of the Policy}

The environmental policy of Ethiopia also lists key guiding principles intending to lay base for specific strategies, programmes, and implementations as well as to serve as standards against which behaviors, actions, and decisions of individual humans and organizations relating to environment have to be checked to identify whether they conform to the policy goals and objectives discussed above. 
The policy in its section 2.3a states that "Every person has the right to live in a healthy environment" [11]. For me this principle is not doing justice to all members or residents of the natural world. Because it recognizes only the right of human beings to live in a healthy environment by denying the right of the other forms of life to do so. It is clear that the health of the environment depends on the interdependence and mutual respect among its members, ecological balance, and reciprocal duties of all where each and every one must fulfill the duty and responsibility that it/he/she has towards other co-members of the natural environment. However, in case of this principle of the policy human beings were considered as superior to the rest members of the natural world where humans enjoy the right to live in a healthy environment at the expense of their co-members (plants, animals, species, and ecosystems). Instead of this principle that I rejected for the above indicated reasons I suggest an alternative principle that states "Every entity that exists in the natural world has the right to live in a healthy and safe environment".

Section $2.3 \mathrm{~b}$ of the policy states:

Sustainable environmental conditions and economic production systems are impossible in the absence of peace and personal security. This shall be assured through the acquisition of power by communities to make their own decisions on matters that affect their life and environment [11].

This guiding principle of the policy emphasizes the importance of peace which is mandatory in order to realize environmental well-being. However, it fails to take into account the concern and proper care that other beings in the natural world deserve through being recognized as plain members of the planet earth together with their human fellow members (Informant: Yeyesuswork Bekele). In other words, it must have extended the horizon of togetherness in a manner that is inclusive of the interests of all that exist in the environment.

The reason why I appreciate the policy on the ground that it recognizes the maintenance of peace and security for the sake of ensuring environmental well-being is due to the fact that absence of peace in general and the presence of war and instability in particular would seriously threaten the natural world and its inhabitants. For example, if we look at the case of insurgent armed groups in the name of freedom fighters, especially in most African countries where the culture of democracy, good governance, bargaining and constructive negotiation is not promoted yet, these armed groups reside in jungles or natural forests in order to attack the governments that they perceive are illegitimate and undemocratic through applying hit and run tactics or gorilla fight.

The same thing holds true if we look at the case of Ethiopia where a number of armed groups operate in different natural forest parts of the country in the name of freedom fighters. These armed groups would inevitably cause damage to the natural forests in general and the wildlife residing in the forests in particular because they use military weapons either to attack or defend government forces on the one hand, they would depend on the wildlife residing in the forests for their survival, on the other hand. In other words, most sources of these armed groups come from the plants, animals, and other beings in the forests. As a result, lack of peace and instability that arise from the conflict and war between the government and these armed groups seriously threaten all forms of life that reside in the environment that falls under the boundary of the country. Therefore, paying attention to promoting lasting peace that is enshrined in the environmental policy of Ethiopia is something that has to be given credit, however, it must have stated that from the point of view that worries about the fate of all entities in the natural environment than emphasizing only the interest and safety of human beings.

Section 2.30 of the policy states that "Local, regional and international environmental interdependence shall be recognized" [11] as its guiding principle. I think this principle of the policy is perhaps one of the policy's qualities. Because as I have already established in the introductory part of my thesis environmental crisis does not respect the boundary of individual states. Therefore, it would be imperative to create joint ventures with the international community in one or another to work hand in hand to tackle environmental crisis that is trans-boundary issue. In this case this principle of the environmental policy of Ethiopia, if followed by practical implementation would result in positive implications to enter into constructive negotiations and initiatives with other individual states, international organizations, and the international community in general to come up with "adaptation" and "mitigation" mechanisms that could contribute a lot to the effort of averting global environmental crisis.

In its section $2.3 \mathrm{q}$, the environmental policy of Ethiopia states as one of its guiding principles that "Species and their variants have the right to continue existing, and are, or may be, useful now and/or for generations to come" [11]. For me, this principle of the policy is good in one aspect and bad in another aspect, when we look at it from the perspective of "environmental justice". The good aspect is in that it accepts and recognizes the right of species and their variants to continue existing, however, it also has a bad aspect in that it accepts and recognizes the right of the species and their variants to continue to exist not for their own sake but as instrumental to human (current and future generations) ends. I believe that the latter aspect of the principle makes it anthropocentric because it is in a position to worry about the fate of the current generation and the future generation of human beings with no concern even for the intrinsic value and interest of the present generation of other forms of life. Therefore, I argue that this principle must have been stated as "Current generation and future generation of both humans and other species and their variants have the right to continue existing, for the sake of their own good".

\subsection{Analysis and Critical Assessment of the 2011 Climate-Resilient Green Economy (CRGE) of Ethiopia}

Besides, the above discussed 1997 environmental policy, 
the FDRE government has initiated CRGE in 2011 envisioned with achieving middle-income status by 2025 in a climate-resilient green economy. The reason behind the initiative is the belief that the conventional development path would, among other adverse effects, result in a sharp increase in GHG emissions and unsustainable use of natural resources. As it would be difficult to deal with each and every issue that the initiative raises exhaustively, under this section I shall present and critically evaluate the major pillars and core principles of the document. In its introductory part, the initiative states:

As a responsible member of the world, Ethiopia is also aware of the important role that developing countries play in fighting climate change, and has consequently taken on a constructive role in international climate negotiations. Ethiopia's ambition to become a "green economy frontrunner" is an expression of its potential for and belief in a sustainable model of growth [12].

Comparatively speaking, this initiative seems more cognizant of the dynamism in the global status of the natural environment as well as the importance of emphasizing the issue of climate change as an independent and top priority agenda as related to the 1997 environmental policy of Ethiopia (Informant: Sadat Yimam). Moreover, as we understand from the above passage it stresses the role of developing countries like Ethiopia in fighting climate change. I think this is also mandatory since there is a "negative GHG (Greenhouse gases) emissions balance" between the developed countries and the developing ones because the former are more industrialized which in turn resulted in more emissions of GHG (mainly $\mathrm{CO} 2$, N2O, and methane) to the natural world. Therefore, I believe that this kind of lobby that demands the developed countries in particular to internalize the costs and impact of their actions on the environment and to pay their fair share plays a pivotal role in the effort to realize environmental justice. But this does not mean that the developing countries are exempted from the duty though the magnitude of their contribution to the present climate change vary.

However, there are still indicators that this initiative is also founded on the anthropocentric or human centered approach to the natural environment. One of such indicators is the very vision of the initiative itself that reads "To achieve middleincome status by 2025 in a climate-resilient green economy" [8]. It also raises issues related to Gross National Product (GNP) and Gross Domestic Product (GDP) elsewhere in its claims which shows that its motive is more of socioeconomic development. Another evidence that this initiative is also anthropocentric is in that it explicitly states:

Implementing the initiatives would also offer important co-benefits. For example, it would improve public health, through better air and water quality, and would promote rural economic development by increasing soil fertility and food security [12].

Hence, it would be safe to argue that both documents relating to Ethiopia's environmental policy (the 1997 EPE and the 2011 CRGE) are founded on purely anthropocentric or human centered approach to the environment. In other words, they were driven by the idea that plants, animals, species, and ecosystems possess mere instrumental value i.e. they all are means to human ends lacking value for their own sake. Moreover, the initiative states:

To support its growth, Ethiopia has managed to attract more foreign investment. Foreign investment has increased from less than USD 820 million in $2007 / 08$ to more than USD 2 billion in the first half of the 2010/11 fiscal year [12].

It is clear that these Foreign Direct Investments (FDI) will have a far reaching negative consequences on the environment in general and on the life of the local communities in general, however, the initiative appreciates these achievements and encourages attraction of more FDI instead of suggesting and recommending alternative domestic means of development such as effectiveness and efficiency of traditional farming systems in order to narrow the international import-export trade deficit or imbalance. Therefore, I argue that this claim of the initiative backfires since it is trying to criticize the developed countries for undertaking the same or similar activities that they are now being invited to undertake in Ethiopia. The document further stipulates:

Our vision of a Climate-Resilient Green Economy does represent a major shift away from conventional development approaches and will require significant international support. We are eager to take up this challenge and have created the CRGE initiative in order to identify sustainable and climateresilient paths to economic growth. It builds on our strengths and has the potential to deliver high returns to its people, its economy, and its environment [12].

This claim reveals the commitment of Ethiopian government to make paradigm shift in the conventional development approaches that might result in sweeping measures and changes in the persistent presuppositions relating to the relations between human beings and the natural environment, if followed by concrete and practically applicable strategies and action-plans. Another important claim of the above passage of the document is its concern for environment though it was primarily concerned with the return for the people and the economy. I argue that in the upcoming formulation or revision of policy, strategy, initiative, and legislations relating to the environment, Ethiopia must claim the protection of the natural environment in general in which human beings have to be considered as plain members rather than putting humans at center which has been the case in the ones devised so far.

\section{Conclusion and Recommendations}

\subsection{Conclusion}

The main objective that has been addressed in this thesis is the establishment of sound arguments that could serve as a ground on which the environmental policy of Ethiopia could be rationally criticized. The problem dealt with in this thesis could be best defined and explained by looking at the larger 
picture of the issue of which it is part and parcel. The larger picture in this context represents or depicts the global environmental crisis that is resulting in the suffering of all that exist in the natural world. In an attempt to resolve this common crisis we have been experiencing commitments of the countries of the world either individually or collectively through creating joint ventures that resulted in a number of initiatives and conventions regarding environmental issue. However, it has been argued throughout this thesis that most of the philosophical foundations and principles and values underlying those commitments made so far are problematic by themselves. The main reason that makes them problematic is that they are founded on the very assumption and prejudice that gave birth to the crisis that the countries either individually or collectively aspire to resolve. These assumption and prejudice are present in the conventional approach to the environment where all non-human beings and even the nature are regarded as mere means to human ends which is taken for granted by many for only being part of the favored community, i.e. the community of human beings. I believe that this kind of trying to resolve a problem with the same mentality that created the problem is good at intensifying the challenge. Accordingly, the case of conducting philosophical enquiry into the environmental policy of Ethiopia has to be understood as part of the larger picture of the problem that has got more emphasis here for the sake of making it as specific as possible, otherwise it would have been very difficult to manage to arrive at this conclusion.

I believe that the environment in general and the environment in Ethiopia in particular have faced injustice. One of the main reasons for this injustice is the conventional approach to the environment present in many life styles, cultural practices, and even in environmental policies that see nature and non-human beings in the natural environment as merely instrumental to satisfy human needs and wants and lack interests and intrinsic values in their own and for their own sake. In other words, this conventional approach called anthropocentric or human centered approach to the environment claims that the non-human members of the natural environment do not deserve the right to get access to moral standing or concern as they lack interests of their own and not worth living for their own sake except as means to human ends. Therefore, it would be imperative to rethink how we behave and act in our relations with the natural environment which in turn requires critical evaluation of environmental policy which is legally coercive to shape our behaviors and actions towards the environment. "A thing is right when it tends to preserve the integrity, stability, and beauty of the biotic community. It is wrong when it tends otherwise" [13].

It is because of my believe in the importance of environmental ethics and the philosophical discourse in it for developing an attitude that does justice to the environment or the one that accords proper care and due respect to life and nature in general, and similarly vital in devising an environmental policy that is ethical in regulating the relations between human beings and the natural environment that led me to present environmental ethics in its broader context; the need for environmental ethics; the major theories and approaches of environmental ethics, and the relationship between environmental ethics and environmental policy in detail in chapter two. Though I have presented the major approaches and theories of environmental ethics in detail with their respective claims and in line with my own critics, now, I shall forward only few of them as concluding remarks. "[T] he idea of a human-centered nature, or anthropocentrism, explicitly states that humans are the sole bearers of intrinsic value and all other living things are there to sustain humanity's existence" [14]. I have argued that the anthropocentric view or the human centered approach to the environment that claims nature and non-human members of the natural world are all means to human ends has been dominating the way most societies think and act in their relations with the natural environment though its origin was said to be the Western culture where consumerism used to be the guiding way of life. Because that pattern of thinking has been inevitably transferred to societies across the world via 'modern education', imperialism, colonialism, expansion of religions, and other modes of interaction with the rest parts of the world. Another reason is that it appears to be true that selfishness is inherent in the nature of human beings because the human community has been considering itself superior to the non-human entities in the natural environment claiming that its members are the only rational animals and consequently the only ones who deserve moral standing or concerns. But I believe that it remains controversial whether human beings are the only rational animals. Even if it is true that humans are the only rational animals, I argue that it follows they are abusing their capacity to reason out by using it to marginalize and exploit the non-human beings that they perceive as lacking rationality. Logically, it follows that human beings are irrational animals causing harm to "nonrational" beings in the natural environment, which shows that the degree of immorality of human beings is very high because they did the harm to "the non-rational" beings using their advantage of possessing the ability to reason out. Therefore, these all are directly or indirectly the consequences of the dominance of the anthropocentric view in the conventional approach to the environment and this entails that this approach continues to exacerbate the environmental crisis if not replaced by another approach that does not favor one community of the natural environment over the other.

I argued that one of the major weaknesses of the environmental policy of Ethiopia is lack of learning from good practices related to protection of the environment that indigenous cultural groups of Ethiopia possess. Workineh Kelbessa [5] argues "little attempt has been made to include peasant farmers and pastoralists in the formulation and implementation of various policies". I also argued that if the environmental policy of Ethiopia has been able to learn from the environmental ethics of the local community it would have been able to use the opportunity to get the cooperation 
and obedience of the people at ease. Because in the first place, they feel concerned and cared for, and secondly, it would be quite easy for them to realize and implement the methods and ways of thinking that they have lived with for a life time. Yoshida Fumikazu [10] argues:

If we are to have any hope of overcoming the diversifying problems that affect the environment, many actors will have to play a part, not only governments but citizens, too, and, of course, the corporations, and the various actors will need to make use of a variety of policy instruments.

I have also stressed that the theory and practice of environmental ethics are imperative to formulate an environmental policy that is ethical. Because the normative principles and standards that serve as the pillars of an environmental policy in shaping, guiding, and governing actions and behaviors of individual human beings and institutions must pass through speculations, critical evaluation, and rational debate and critics if we are to have an environmental policy that does justice to the environment. And this procedure in which the principles and standards should pass includes elements of philosophical discourse on the major approaches and theories of environmental ethics in which each claim and proposition has to be supported by convincing reasons. This implication of environmental ethics on the art of formulating environmental policy and shaping attitudes relating to the relations between human beings and the natural environment makes it both theory and practice, because it is an attempt to apply those justifiable environmental ethical principles to dissolve the unjustified conventional approaches to environment as well as to resolve the critical environmental problems and challenges in particular and to avert the global environmental crisis in general. That is why I analogously presented that an environmental policy formulated without consulting environmental ethics and its practitioners is the same as trying to treat a patient without consulting a physician or with no diagnosis of the patient's disease. As trying to treat a patient without consulting a physician and with no proper diagnosis of his/her disease either makes the patient stay with the disease or intensifies it which might even result in untimely death of the patient; an attempt to formulate an environmental policy at global, regional, and national level without applying proper knowledge and rational discourse of environmental ethics would similarly result in either continuing the suffering from the present status of environmental crisis or facing a more complicated and dangerous environmental crisis. A "tragedy of the commons" occurs when individuals, sharing a resource held in common, each act in self-interest and the collective result progressively degrades the collective resource, illustrated by shepherds placing more and more sheep on land held in common [15]. Hence, the study of environmental ethics and the philosophical discourses we find in it are mandatory if we are to manage and overcome environmental crisis.

In general, this thesis has been arguing either explicitly or implicitly that the environmental policy of Ethiopia is not ethical seen from the perspective of holistic environmental ethics and principles of environmental justice which is the view that this thesis has been reasonably arguing for elsewhere. What makes it unethical is that the policy strives to secure and safeguard the interests and rights of human beings at the expense of the rights and interests of all nonhuman beings in the natural environment and the nature which after all backfires with the goal of the very existence of the policy, because it has been named as "the environmental policy of Ethiopia", however, in effect it found to be " a policy of securing the interest of Ethiopians (humans) at any cost of the interest of any other being in the environment" based on my thesis's conclusions of the analysis and critical evaluation of the specific issues and claims stated in the policy documents.

\subsection{Recommendations}

On the basis of the conclusions made in this thesis, I would like to suggest the following major recommendations:

1. While formulating or revising environmental policy, concerned government organs, professionals, and experts should take the relevant indigenous environmental ethics into account.

2. Inputs from the ideas and suggestions of environmental theorists and ethicists, biologists, agronomists, economists, and other professionals must be incorporated into the environmental policy debate in Ethiopia.

3. Environmental ethics as a discipline must be incorporated into the formal educational curriculum of secondary and tertiary levels of education of Ethiopia.

4. As a member of various international organizations and the international community at large, Ethiopia must strive to exert a meaningful and positive influence that would lobby those international institutions and the international community at large to come up with initiatives and conventions that do justice to the environment.

5. The government and the people of Ethiopia must revisit both the domestic and the international legal frameworks and contexts from which the present anthropocentric or human centered environmental policy documents of the country emanated.

6. The overall goal and objectives of the environmental policy of Ethiopia must be revised and revitalized in a manner that could address the interest of all beings that exist in the natural environment since the existing ones are doing otherwise.

7. The purpose of the environmental policy documents of Ethiopia must be revisited and revised so as to shape peoples' attitude, actions, and behaviors in a way that accords proper care and due respect to all forms of life and the environment in general, instead of propagating the need to preserve and conserve the environment merely for the sake of securing human interests (the current generation and the generations to come of human beings).

8. Theory and practice of the concept so called "illegal 
hunting" must be abolished from the realm of Ethiopia's environmental policy and other relevant legislations, because logically it implies and encourages the presence of "legal hunting".

9. The concept of the need to promote peace, health, and well-being of humans emphasized in the environmental policy of Ethiopia must be extended and expanded to include the concern for all beings in the environment.
10.Last but not least, provisions of the recently enacted proclamations of the FDRE on the issue of environment must be amended in a manner that avoids the loopholes that made some of the articles and subarticles open to subjective interpretations through replacing them with clear, price, applicable, and measurable rules and regulations.

\section{List of Abbreviations and Acronyms}

$\begin{array}{ll}\text { CRGE } & \text { Climate-Resilient Green Economy } \\ \text { EIA } & \text { Environmental Impact Assessment } \\ \text { EPA } & \text { Environmental Protection Authority } \\ \text { EPE } & \text { Environmental Policy of Ethiopia } \\ \text { EPRDF } & \text { Ethiopian Peoples' Revolutionary democratic Front } \\ \text { FDI } & \text { Foreign Direct Investment } \\ \text { FDRE } & \text { Federal Democratic Republic of Ethiopia } \\ \text { GDP } & \text { Gross Domestic Product } \\ \text { GHG } & \text { Green House Gases } \\ \text { GNP } & \text { Gross National Product } \\ \text { IMF } & \text { International Monetary Fund } \\ \text { IUCN } & \text { International Union for Conservation of Nature } \\ \text { MNCs } & \text { Multinational Corporations (MNCs) } \\ \text { MOA } & \text { Ministry of Agriculture } \\ \text { SAP } & \text { Structural Adjustment Program } \\ \text { UN } & \text { United Nation } \\ \text { UNCED } & \text { United Nations Conference on environment and Development } \\ \text { UNEP } & \text { United Nations Environment Programme } \\ \text { USD } & \text { United States Dollar } \\ \text { WB } & \text { World Bank } \\ \text { WCED } & \text { World Commission on Environment and Development } \\ \text { WWF } & \text { World Wide Fund for Nature } \\ & \end{array}$

\section{Appendix}

Interview Guides for Ethiopian Environment, Forest and Climate Change Commission Staff Members/Policy Makers and Analysts:

1. Who do you think should take part in the process of making the environmental policy of Ethiopia?

2. Do you believe that all the concerned stake holders have participated in the process of formulating the environmental policy of Ethiopia?

3. Please, Could you list and explain the included stakeholders with justifications of why they deserve to be included or why not others other than the ones took part in the policy debate?

4. Could you mention and explain the philosophical and theoretical foundations of the environmental policy of Ethiopia?

5. Do you think that the environmental policy of Ethiopia is an inclusive or holistic one? Does it address the interests and issues of all members of the natural environment of the country in a comprehensive way?

6. How do you see the environmental policy of Ethiopia from the perspective of learning from and incorporating the relevant indigenous environmental ethics?

7. How do you consider the extent to which the environmental policy of Ethiopia might be influenced by international organizations and donors?

8. How do you see the international legal frameworks (the conventions and agreements relating to the issue of environment that Ethiopia has ratified) and the domestic legal frameworks like provisions of the country's constitution and other laws regarding environment vis-à-vis the environmental policy of Ethiopia?

9. What do you think are the major limitations/weaknesses of the environmental policy of Ethiopia?

10.Could you mention some of the major strengths/qualities of the environmental policy of Ethiopia?

11. What would you suggest to overcome the problems and challenges that might face the environmental policy of Ethiopia? 


\section{Acknowledgements}

First and foremost, I would like to express my profound gratitude to Professor Workineh Kelbessa, my advisor, for his tremendous insight and scholarly support in the course of this thesis. His constructive feedback, comments, and suggestions added a great value to this work.

I am grateful to Ethiopian Environment, Forest, and Climate Change Commission policy makers, analysts, and experts (Dr. Ayele Hegena, Mrs. Yeyesuswork Bekele, Mr. Belachew Hailemariam, Mrs. Sadat Yimam, Mr. Wondwossen Tadese, and Mr. Yohannes Jeilu) who have provided me with the desired information for this thesis.

I also owe a special debt of gratitude to my parents, especially my mother, Ajebush Mekonnen, for their unconditional love and support all through the time, if it were not for their unlimited support and encouragement, I wouldn't have been the person I am now. Likewise, I would like to express my deepest gratitude to my wife, Chaltu Abdeta, for her understanding and patience while I spent much time away from her for my graduate study and thesis, as well as for her unreserved support and encouragement all the way through.

Last but not least, I would like to thank Mettu University for allowing me to quit my teaching duties and assignments for four semesters to complete my post graduate study and thesis, as well as for sponsoring the financial requirements for this thesis and my graduate study too.

\section{References}

[1] Cochrane, Alasdair. (2006) "Environmental Ethics". The Internet Encyclopedia of Philosophy, Available at: http://eprints.lse.ac.uk/21190/.

[2] Boutros-Ghali, Boutros. (1992a) "Extracts from closing United Nations Conference on environment and Development statement," in an UNCED summary, Final Meeting and Round-up of Conference, June 14, UN Document ENV/DEV/RIO/29, 14 June.

[3] Murove, Munyaradzi Felix. (2009) “An African Environmental Ethic Based on the Concepts of Ukama and
Ubuntu", in Murove, Munyaradzi Felix (ed.). African Ethics: An Anthology of Comparative and Applied Ethics. Scottsville: University of Kwazulu -NatalPress, pp. 314-331.

[4] Melaku, Bekele. (2008) "Ethiopia's Environmental Policies, Strategies and Programmes", in Taye Assefa (eds.). Ethiopia's National Policies, Strategies and Programmes. Addis Ababa: Forum for Social Studies, pp. 337-370.

[5] Workineh, Kelbessa. (2014) "Can African Environmental Ethics Contribute to Environmental Policy in Africa?" Environmental Ethics, 36: 31-61.

[6] Keeley, James and Scoones, Ian. (2003) Understanding Environmental Policy Processes: Cases from Africa. London: Earth scan Publications.

[7] Hoben, Allan. (1995) "Paradigms and Politics: The Cultural Construction of Environmental Policy in Ethiopia," World Development, 23 (6): 1007-1021.

[8] Kalavathy, Sitinuraisyah. (2004) Environmental Studies. Tiruchirappalli, India: Bishop Heber College.

[9] Kumarawsamy, Kumbar. (2004) "Geohydrological Characteristics and Water Management Strategies for a SemiArid River Basin of South India", Indian Journal of Geomorphology, 8 (1 and 2): 123-128.

[10] Fumikazu, Yoshida. (2012) "The Theory of Environment Governance", in Lecture on Environmental Economics, Chapter 4: 75-103.

[11] Federal Democratic Republic of Ethiopia. (1997) Environmental Policy. Addis Ababa: Environmental Protection Authority in Collaboration with the Ministry of Economic Development and Cooperation.

[12] Federal Democratic Republic of Ethiopia. (2011) ClimateResilient Green Economy (CRGE) Initiative. Addis Ababa: FDRE.

[13] Leopold, Aldo. [1949] (1966) A Sand County Almanac with Other Essays on Conservation from Round River. New York and Oxford: Oxford University Press.

[14] MacKinnon, Barbara. (2007) Ethics: Theory Contemporary Issues, 5thedn, Thomson/Wadsworth, Belmont, California.

[15] Hardin, Garrett. (1968) "The Tragedy of the Commons," Science 162: 1243-48. 